\title{
The Relationship between Social Identification and Sport Participation amongst Staff of Developmental and Maintenance of Sports in Iran
}

\author{
Kaveh Khabiri \\ Faculty of Humanities \\ Islamic Azad University of Ashtian, Arak, Iran \\ sepka_kh@yahoo.com \\ Sepideh Mehraein \\ Faculty of Education \\ University of Malaya (UM), Malaysia \\ sepideh.mehraein20@gmail.com
}

\author{
Bahram Ghadimi \\ Faculty of Humanities \\ Islamic Azad University, Science and \\ Research Branch, Tehran, Iran \\ B.ghadimi@gmail.com. \\ Aida Mehrad \\ Faculty of Psychology \\ UniversitatAutònoma de Barcelona \\ (UAB), Spain \\ aida_238@yahoo.com.
}

\begin{abstract}
Social identification determined as one of the imperative factor that specialized one society from the one. In fact, this factor has been impacted by various items such as sport participation and appears comprehensively. Sport participation has considerable influence on health of society and conducts individuals' identification in different ways. The present study focused on the relationship between social identification and sport participation amongst 270 staff who are working on developmental and maintenance of sports in Iran. The data has been got based on Social Identification survey, and Participation Motivation Questionnaire (PMQ) (Gill, Gross, \& Huddleston, 1983; Safarinia, Aghayousefi, \& Mostafaei, 2014). The results showed that the staff sport participation as independent variable linked with social identification; In other words, sport participation of staff at workplace has substantial role on sport identification that appeared as dependent variable in this survey. The staff who considered on team working as participation and supply this main factor on their daily life shown better social identification and performance.
\end{abstract}

Keywords: Social Identification, Sport Participation, Staff, Iran

Received 9 Mei 2018/Accepted 23 June 2018 @ JEHCP All rights reserved

\section{Introduction}

One of the important factor in every society that can categorized the different of societies is social identification. As matter of fact, this factor referred to the content of the identity itself and specified the strength of the connotation with a precise social category (Ellemers, Koreas, \& Ouwerkerk, 1999). Based on the investigation of some researchers such as Ellemers, Spears, and Doosje (2002), the social identification is one of the central aspect of self; and also, it stated to the nature or content of a specific identity that related also to society. In general, it has included brilliant positive and negative features. The social identification likewise presumed as an essential 
factor in sport society and it can so significant for athletics. Social identification has concluded in different view and determines the individuals 'way. As a matter of fact, the social identification referred to the identification of the individual (Lataie, 2003).

Sport participation is as one the critical factors that impacts on health of society and individuals. In actual fact, sport is one of the vital factor in group participations or team working, and most of researchers have been considered on sport and determined it as "small word in the world". In other words, the sport plays substantial role on health, entertainment, identification, and prosperity.

Reality, the sport is necessary for every society; because the healthy society needs well and happy power. In recent years, recognizing aims and motivations in sport participation has been deliberated by supporters and researchers in the sport area; additionally, this issue is cause of knowing important factors in sport and strategic planning. Definitely, sport has vivid role on life span, cultural growth, and recreation. In the sport participation area classification is so essential; in this regard, the researchers in university of Michigan focused on sport area and emphasized that sport amongst young people (16-38) is so imperative and improve them in team working. In this survey likewise explained that having regular sport activity does not have any negative consequences on young people activity process (“University of Michigan”, 20I3). Furthermore, social identification determined as a main dependency factor in society that influenced by performances such as team Sport participations motivate mental and moral of individuals' performance and conduct them to main goal. In sport participation some factors such as success, grouping, physical and mental fitness, social position, condition, skill, entertainment, and friendship are very important that in the current study will be surveyed (Imani \& Keyzaghan, 2003). Conversely, some of the researchers such as Darabi, Ghayini, and MomeniVand (2009); Jackson (2005), also Jahromi and Hashemi (2005) reported sport and activities that related to it does not have meaningful contribution on social identification of individuals and their performance at society.

Based on previous studies, Duncan (1990) explained that social identification via sport has considerable process in learning and social development. The researcher referred to reactions in sport's world, and believed that individuals' relationship in sport area makes brilliant social identification. In 2002, RahmatAbadi and Agha Bakhshi determined the recognizing social identification on individuals' view and differences between modern and traditional societies. 
Similarly, Horn, Schaufeli, Wilmar, and Enzmann (2006) emphasized on sport features that plays great role on individuals' presentation in society. In the research of Bastos, Salguero, GonzálezBoto, and Márquez (2006); Wicker, Breuer and Pawlowski (2009); and "Understanding the barriers to participation in sport" 20I2, described that sport participation plays main role on individuals' life style that makes brilliant the presence and identification of individuals at society and conduct them correctly.

Furthermore, the significant of this study is to make brilliant role of sport in different societies and also illustrate that how much participating in sport activity can be useful for individuals specifically for staff who are working in different workplaces; also, it increases the amount of effective presence of staff at work. Moreover, the present study focused on the role of staff sport participation on social identification at developmental and maintenance of sports in Iran; and determined considerable importance of activity and presence of staff at sport area. In overall, this research emphasized on sport and its vital role amongst staff in dissimilar workplaces; and its support via, managers and ministry of sport.

\section{Methods}

\section{Participants}

In the present study has been focused on 270 staff that who were working on developmental and maintenance of sports in Iran. Random sampling methode was used to recruit the participants.

\section{Measurement}

The measurements of the present survey comprised: Social Identification Questionnaire that proposed by Safarinia et al. (2014) for measuring social identification that included 20 items. The Cronbach's alpha of the questionnaire was 0.71 . In addition, the study also used Participation Motivation Questionnaire that developed by Gill et al. (1983) for measuring sport participation. The Cronbach's alpha of this questionnaire was 0.76 .

\section{Data Analysis}

The current research has been used descriptive statistics and Pearson correlation coefficient via SPSS version 23 statistical software. 


\section{Results}

Tablel shows the results of association between sport participations'aspects and social identification, that there is positive significant relationship between social identification and success $(r=.60 \mathrm{I}, p<.00 \mathrm{I})$; also, there is meaningful relationship between social identification and grouping $(r=.424, p<.001)$; physical and mental fitness was also found to has positive significant relationship with social identification $(r=.492, p<.001)$;social position likewise has significant relation with social identification $(r=.591, p<.001)$; also, skills has significant association with social identification $(r=.489, p<.001)$; friendship was also found to has positive substantial connection with social identification $(r=.566, p<.001)$; and entertainment has meaningful relation with social identification $(r=.402, p<.00 \mathrm{I})$.

Regarding to these results, sport participation has significant relationship with social identification. In actual fact, sport participation of staff has remarkably contribution on their social identification and performance. The staff who have high level of sport participation present high level of social identification and activity in the society and workplace; and they show appropriate relation with their colleagues.

Table I

Relationship between Social Identification and Sport Participation

\begin{tabular}{|c|c|c|c|c|c|c|c|}
\hline Variable & $\bar{I}$ & 2 & $\overline{3}$ & 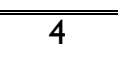 & 5 & $\overline{6}$ & $\overline{7}$ \\
\hline $\begin{array}{l}\text { I Social } \\
\text { Identification }\end{array}$ & & & & & & & \\
\hline 2 Success & $.601 * *$ & & & & & & \\
\hline 3 Grouping & & $.424 * *$ & & & & & \\
\hline $\begin{array}{l}4 \text { Physical and } \\
\text { mental fitness }\end{array}$ & & & $.492 * *$ & & & & \\
\hline 5 Social Position & & & & $.591 * *$ & & & \\
\hline 6 Skill & & & & & $.489 * *$ & & \\
\hline 7 Friendship & & & & & & $.566 * *$ & \\
\hline 8 Entertainment & & & & & & & $.402 * *$ \\
\hline
\end{tabular}




\section{Discussion}

The researchers in social science area believed that every society needs some basic and principles roles; in this regard, the presence of active individuals in different parts of society (social, politics, art, sport etc.) presumed so importantly that should be considered, carefully. In actual fact, the society has great influence on values and identification of individuals (Kasomo, 20I2). Regarding the objective of the current investigation that determined the important role of staff sports participation based on their social identification at Developmental and Maintenance Sports in Iran; the outcomes shown that sports participation linked with social identification. This result means that whatever the amount of social identification firm in high position some factors such as success, grouping, physical and mental fitness, social position, friendship, and entertainment growth remarkably amongst staff, that undoubtedly related to the attitudes and support of society, government, and workplace. In other words, the staff based on their participation in sports activities that play as positive motivators exposed more present at the workplace; in addition, illustrated better social identification about them. Generally, success, grouping, physical and mental fitness, social position, skills, friendship, and entertainment as effective sub factors of sports participation motivate staff, and they demonstrate the high level of social identification at the workplace.

According earlier investigations, RahmatAbadi and Agha Bakhshi (2002); Bastos et al. (2006); Horn et al. (2006); Wicker (2009) emphasized on the substantial role of sport; they likewise reported the sport participation has brilliant role on individuals' personal and social life style and creates brilliant presence and identification from them at the social order.

Based on the previous surveys, sport and also the amount of individuals' participation in any type of sport and competition were the cure of research; while the current study considered to the main role of sport and staff participation that formed their identification at society and make staff role as brilliant factor at workplace. In actual fact, the study shown that how sport participation that included success, grouping, physical and mental fitness, social position, skills, friendship, and entertainment create great challenge for staff and they can know themselves more and more, and also show their identification at society, clearly. 


\section{Conclusion}

Concerning to the results of the present study, every society required high level of facilities and accommodation. These factors appeared based on accurate strategic. The sport participation is one of the critical factors that provided positive situations in every situation. According to the aim of this research that dedicated on sport participation and its impact on social identification and sport participation, the results are corresponding with RahmatAbadi and Agha Bakhshi(2002), Bastos et al. (2006), and Staudt (2010). On the other hand, the findings are different with Darabi et al. (2009); Jackson (2005); and Jahromi (2005).

Based on the results of the study and previous research, the role of social identification is so important; actually, subject of identification is one of the critical motivations in the recent years that has been considered by majority of scientists in sport area. In other word, developing social identification and bearing in mind various views of behavior and personality is very critical. Furthermore, managers and also ministry of sport should be support those who are interested in any kind of sport and provide appropriate sport facilities based on their requirements. Overall, participation in sport has imperative role at effective staff's performance at workplace.

\section{Limitation}

The main limitation of the current research is related to the lack of studies in the sport participation area and responding satisfaction.

\section{Suggestion}

This study just focused on staff that are working in the specific company in Iran, for the future research suggested concentrate on staff in different cities of Iran and compare them together. Also, recommended the researchers consider to age as main factor in their surveys. Additionally, focusing on various features of society based on different references has been suggested.

\section{References}

Bastos, A. S., Salguero, A., González-Boto, R., \&Márquez, S. (2006). Motives for participation in physical activity by Brazilian adults. Journal of Perceptual and Motor Skills, 102, 358-367. 
Darabi, M., Ghayini, A., \&MomeniVand, P. (2009). Investigating the Cultural Factors Affecting the Attitude of Sporting Activities in Women 25 to 40 Years Old in Tehran. Research Institute of Humanities and Cultural Studies, Sport Management Studies (Institute of Physical Education), 3.

Duncan, K. F. (1990). Social Research: An International Quarterly Post-Totalitarian Politics: Ideology Ends Again. Arien Mack, Editor, 57, (3) 665-687.

Ellemers, N., Kortekaas, P.,\& Ouwerkerk J. (1999). Self-categorization, commitment to the group and social self-esteem as related but distinct aspects of social identity. Eur. J. Soc. Psychol. 28:37I-98.

Ellemers, N., Spears, R., \& Doosje, B. (2002).Self and social identity. Annu. Rev. Psychol, 53,16I-186.

Gill, D.L., Gross, J.B., \& Huddleston, S. (1983). Participation motivation in youth sports. International Journal of Sport Psychology, 14, I-I4.

Horn, J. E. V., Schaufeli Wilmar, B., \&Enzmann, D. (2006). Teacher Burnout and Lack of Reciprocity. Journal of Applied Social Psychology, 29(I), $91-108$.

Imani, M. T., \&Keyzaghan, T. (2003). Study effective factors on women identification, Journal of Alzahra University, 45.

Jackson, E. L. (2005). Leisure constraint research: Overview of a developing theme in leisure studies. State College, PA: Venture Publishing.

Jahromi, M., \&Hashemi, H. (2005). Inhibitory factors of sport participation among female employees of Isfahan. Journal of Research in Sport Sciences, 23, I50- 137.

Kasomo, D. (20I2). Factors Affecting Women Participation in Electoral Politics in Africa. International Journal of Psychology and Behavioral Sciences, 2(3), 57-63.

Lataie, GH. (2003). Humor of Ethnic Identity in Iran, Shadegan.

RahmatAbadi, E., \& Agha Bakhshi, H. (2002). Lifestyle and Youth Social Identity, Social Welfare, 5(20), 235-256.

Safarinia, M., Aghayousefi, A., \&Mostafaei, A. (2014). The relationship between social procrastination and social identity and students' academic performance, Social Cognition, 3(2), 123-134.

Staudt, K. (2010). Women, International Development: And Politics. Temple University Press.

Understanding the barriers to participation in sport 2012. Retrieved from http://www.efds.co.uk/how-we-help/research/I87I -understanding-the-barriers-toparticipation-in-sport-april-20I2

University of Michigan 2013. Retrieved fromhttp://mgoblue.com/sports/2017/6/16/sports-m-footblarchive-fbl-guide-20I3-html.aspx

Wicker, P., Breuer, C., \& Pawlowski, T. (2009). Promoting sport for all too age-specific target groups: the impact of sport infrastructure. European Sport Management Quarterly, 9(2), 103II8. 